\title{
Linearisation of a urinary flow transducer
}

\author{
R. Kranse R. van Mastrigt \\ Department of Urology-Urodynamics, Erasmus Universitys Rotterdam, Room Ee 1630, \\ PO Box 1738, 3000 DR Rotterdam, The Nethertands
}

Keywords-Dantec 1000, Flow rate, Flow transducer, Linearisation, Urodynamics,
Urology

Med. \& Biol. Eng. \& Comput., 1995, 33, 835-837

\section{1 introduction}

URODYNAMICS is a subdiscipline of urology concerned with the function of the lower urinary tract on the basis of information in physical signals such as the urinary flow rate, pressures measured in the bladder and the rectum (or abdominal cavity), as well as voltage variations reflecting pelvic floor muscle activity (EMG) (GRIFFrTHS, 1980). This work focuses on the measurement of the urinary flow rate.

In urodynamics, at least two different types of flow meters are in use. The first type simply measures the weight of the voided volume as a function of time. Differentiation of this signal provides an assessment of the urinary fiow rate (COOLSAET and VAN DUYL, 1981; ROLLEMA, 1981). The essential part of the second type of flow meter is a rotating disk. This disk is kept at a constant angular velocity by means of a feedback control system. Urine that hits the disk is accelerated to the circumferential speed of the disk. The extra energy necessary for this acceleration is proportional to the mass of the urine that 'flows through' the device per unit of time. The rotating disk technique has important advantages over the other type of flow meter (TAMMEN, 1971a, b; ROWAN et al., 1977).

As rotating disk flow transducers have a nonlinear transfer function, the output signal should be linearised. In commercial urodynamic measurement systems, such a linearisation is built in by the manufacturer. These complete measurement systems are very expensive and not very attractive to research institutions; real-time output signals are usually not available and the possibilities for signal processing are limited.

We have therefore decided to develop a urodynamic measurement system using a personal computer, an analogue digital convertor and a flow transducer. This work describes a simple linearisation procedure for this type of flow transducer. The method has been tested on six flow transducers.

\section{Materials and methods}

Six rotating disk flow rate transducers* were studied. The output of the transducers was electrically amplified and fed to a

* Dantec Urodyn 1000, Dantec Technical Documentation, Publ. 8701 E. 1988, Dantec Electronic Medicinskog Violenskabeligt Maleudstyr A/S, Tonsbakken 16-18, DK-2740 Skovlunde, Denmark

First received 13 May 1994 and in final form 20 February 1995

(C) IFMEE: 1995
12 bit $\mathrm{A} / \mathrm{D}$ convertor board $\dagger$ in a standard personal computer. The amplifier output was sampled at a rate of $10 \mathrm{~Hz}$. The same amplifier and $A D D$ board were used in all measurements. The input range of the AND convertor was $0-10 \mathrm{~V}$.

The quiescent output of each flow transducer was determined by sampling it for approximately $1 \mathrm{~min}$ (no flow rate applied). Apart from an offset that was digitally subtracted from each sample in subsequent measurements, this yielded an impression of the transducer output variability which places a limitation on the smallest flow rate that can be measured with the device.

Each transducer was tested ten times by pouring in a precise volume of water with a varying flow rate. Care was taken never to exceed the measurable flow rate range. Subsequently, the zero level was measured again. From each sample the offset value was subtracted. The total number of samples in each artificial voiding was counted, and the sum and squared sum of the samples were calculated.

Two hypothetical relationships between transducer output and flow rate were tested: linear and parabolic (second-order polynomial).

For each flow transducer, the following systems of equations (linear in the parameters $a, b_{1}, b_{2}$ and $c$ ) were solved by means of a linear least-squares method:

$$
\begin{aligned}
& V O L_{i}=\sum_{j=1}^{N_{i}}\left(a+b_{1} x_{i j}\right) \\
& V O L_{i}=\sum_{j=1}^{N_{i}}\left(a+b_{2}\left(x_{i j}\right)+c\left(x_{i j}\right)^{2}\right)
\end{aligned}
$$

where $N_{i}$ is the number of samples in the $i$ th voiding $\left(i=1, \ldots, 11\right.$, i.e. including the zero measurement); $a, b_{1}$, $b_{2}$ and $c$ are model parameters; $V O L_{i}$ is the volume poured into the flow meter in the $i$ th measurement; and $x_{i j}$ is the $j$ th sample of the ith measurement (the unscaled output of the A/D convertor).

The systems of eqns. 1 and 2 were solved by means of the SPSS linear regression procedure. This procedure lists the least-squares solutions of the parameters, as well as their standard errors (based on the assumption of independent zero mean and constant variance noise).

Following the calculation of $a, b_{1}, b_{2}$ and $c$, five verification measurements were performed; i.e. four volumes of $400 \mathrm{ml}$ with varying flow patterns and one volume of $30 \mathrm{ml}$ in drops, 


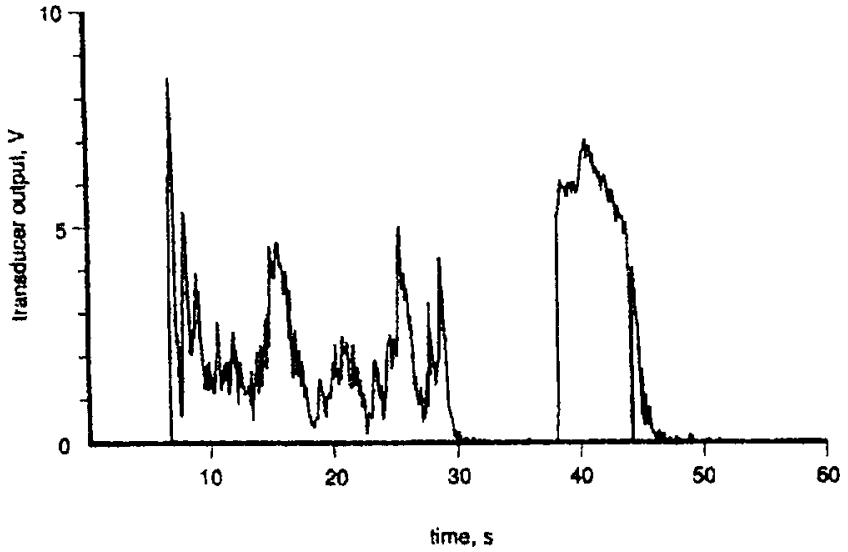

Fig. 1 Output signal of one flow rate transducer when $400 \mathrm{ml}$ of water was poured in

with an average flow rate of $1 \mathrm{ml} \mathrm{s}^{-1}$, were poured into the transducer. We compared these volumes with the volumes calculated using the determined parameters for each individual flow meter. An additional five verification measurements were performed, where the volumes were calculated using the averaged parameters $a_{o w} b_{2 \alpha v}$ and $c_{\alpha v}$ (for the quadratic model only) for all six flow transducers. The absolute values of the differences between the measured and applied volumes were ranked and compared by means of a Mann-Whitney U-test.

Statistical analysis was carried out using the SPSS statistical package.

\section{Results}

Fig. 1 shows the output of one of the transducers when $400 \mathrm{ml}$ of water was poured in; note the wide range of flow rate values that contribute to the linearisation process.

Table 1 lists the transducers' offsets and the standard deviations. Two measurements were performed for each transducer (at intervals of one week). It can be seen that the individual transchucers have quite different offsets but comparable standard deviations.

Estimates and standard errors for $b_{1}, b_{2}$ and $c$ in eqns. 1 and 2 are summarised in Table 2 . The $a$ parameters were zero (as the offset value was subtracted from each sample). From Table 2 the average $b_{2}$ and $c$ parameters were derived $b_{a v ?}=395 \times 10^{-2} \mathrm{ml} \mathrm{s}^{-1} \mathrm{~V}^{-1}, c_{a v}=138 \times 10^{-3} \mathrm{ml} \mathrm{s}^{-1}$

Table I Average and SD of transducer offset (at intervals of one week)

\begin{tabular}{lccc}
\hline $\begin{array}{l}\text { flow transducer } \\
\text { serial number }\end{array}$ & offset $\mathrm{V}$ & $\pm \mathrm{SD} \mathrm{mV}$ & $\begin{array}{c}\text { number of } \\
\text { samples }\end{array}$ \\
\hline 989 & 0.32 & 12 & 641 \\
3835 & 0.33 & 10 & 1814 \\
& 0.44 & 12 & 676 \\
3839 & 0.44 & 12 & 623 \\
& 0.37 & 39 & 558 \\
3841 & 0.36 & 15 & 1071 \\
& 0.36 & 10 & 633 \\
5299 & 0.37 & 12 & 1237 \\
& 0.41 & 15 & 736 \\
5304 & 0.41 & 15 & 1041 \\
& 0.47 & 17 & 604 \\
& 0.50 & 17 & 1557 \\
\hline
\end{tabular}

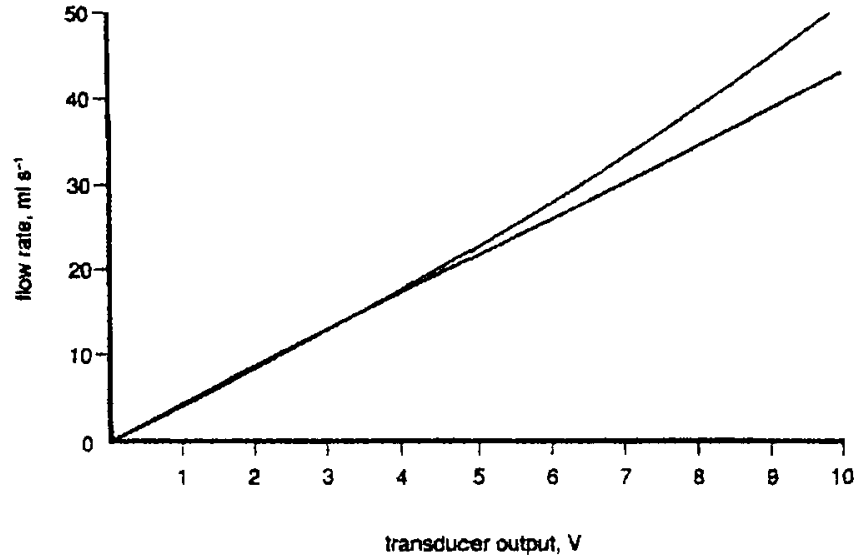

Fig. 2 Linear and quadratic calibration curves for transducer 989.

Table 2 Parameter estimates (plus accuracy estimates) for the six different flow transducers tested (see eqns. 1 and 2)

\begin{tabular}{lccc}
\hline $\begin{array}{l}\text { flow } \\
\text { transducer } \\
\text { serial } \\
\text { number }\end{array}$ & $\begin{array}{c}b_{1} \\
(\text { mean } \pm \mathrm{SD}) \\
\times 10^{-2} \\
\mathrm{ml} \mathrm{s}^{-1} \mathrm{v}^{-1}\end{array}$ & $\begin{array}{c}b_{2} \\
(\mathrm{mean} \pm \mathrm{SD}) \\
\left.\times 10^{-2}\right) \\
\mathrm{ml} \mathrm{s}^{-1} \mathrm{v}^{-1}\end{array}$ & $\begin{array}{c}c \\
(\text { mean } \\
\times 10^{-3} \\
\mathrm{ml} \mathrm{s}^{-1} \mathrm{~V}^{-2}\end{array}$ \\
\hline 989 & $430 \pm 4$ & $392 \pm 2$ & $117 \pm 5$ \\
3835 & $446 \pm 4$ & $410 \pm 4$ & $133 \pm 12$ \\
3839 & $471 \pm 4$ & $377 \pm 4$ & $141 \pm 10$ \\
3841 & $451 \pm 4$ & $411 \pm 2$ & $112 \pm 5$ \\
5299 & $438 \pm 8$ & $393 \pm 4$ & $180 \pm 19$ \\
5304 & $430 \pm 4$ & $385 \pm 4$ & $143 \pm 17$ \\
\hline
\end{tabular}

Table 3 Mean and standard deviation of the diffenences between applied volumes and measured volumes when individual parameter values were used for the linear and the quadratic model, and when averaged parameter values were used (for the quadratic model)

\begin{tabular}{|c|c|c|c|}
\hline $\begin{array}{l}\text { type of } \\
\text { calibration } \\
\text { curve used }\end{array}$ & $\begin{array}{c}\text { volume } \\
\text { difference for } \\
30 \mathrm{ml} \\
\text { measurements } \\
(N=6) \text { in drops } \\
\text { (mean } \pm S D)\end{array}$ & $\begin{array}{l}\text { volume } \\
\text { difference for } \\
400 \text { mi volumes } \\
(N=24) \text {, } \\
\text { continuous flow } \\
\text { (mean } \pm S D \text { ) }\end{array}$ & $\begin{array}{c}\text { volume } \\
\text { difference } \\
\text { pooled } \\
\text { measurements } \\
(N+30) \\
\text { (mean } \pm \mathrm{SD} \text { ) }\end{array}$ \\
\hline $\begin{array}{l}\text { individual } \\
\text { parameters } \\
\text { (linear model) }\end{array}$ & $4.8 \pm 3.6$ & $127 \cdot 2 \pm 41 \cdot 1$ & $102.7 \pm 61.8$ \\
\hline $\begin{array}{l}\text { individual } \\
\text { parameters } \\
\text { (quadratic } \\
\text { model) }\end{array}$ & $6.0 \pm 3.4$ & $4.9 \pm 3.5$ & $5.1 \pm 3.4$ \\
\hline $\begin{array}{l}\text { averaged } \\
\text { parameters } \\
\text { (quadratic } \\
\text { model) }\end{array}$ & $7.7 \pm 3.6$ & $9.7 \pm 7.4$ & $9.3 \pm 6.8$ \\
\hline
\end{tabular}

Table 3 lists descriptive statistics of the absolute values of the differences between applied volumes and measured volumes when individual optimal parameter values were used for the linear and the quadratic transfer function, and when average parameters were used. It follows from these results that the use of a linear model leads to unacceptable inaccuracies for the transducer. Fig. 2 shows the optimal quadratic and linear calibration graphs for a particular transducerई. The straight line and the parabola yield nearly identical results for flow rates $\leqslant 20 \mathrm{ml} \mathrm{s}^{-1}$. This is confirmed by the results of the $30 \mathrm{ml}$ 
measurements (drops) given in Table 3. For higher flow rates, the quadratic term is essential to obtain accurate results; a reference measurement with $400 \mathrm{ml}$ and relatively high and constant flow rates yielded a volume of $406 \mathrm{ml}$ when the quadratic characteristic was used, and a volume of $214 \mathrm{ml}$ when the linear characteristic was used.

Relative errors in the yoided volumes were $6 / 30$ (20\%) for the $30 \mathrm{ml}$ volumes and $4.9 / 400(1 \%)$ for the $400 \mathrm{ml}$ volumes when the quadratic model was used with optimal (i.e. flow meter specific) parameters. These figures were 7.7/30 (26\%) and $9.7 / 400(2 \%)$, respectively, when average parameters were used. When optimal parameters were used instead of average parameters, the difference between the calculated volumes and the actual volumes was significantly smaller for the $400 \mathrm{ml}$ ("continuous flow') measurements ( $p=0.027$ Mann-Whitney U-test). No such statistically significant difference was found for the $30 \mathrm{ml}$ measurements.

\section{Discussion}

Accurate flow meter linearisation (of nonlinear flow rate transducers) is possible using the method described in this work without the use of calibrated flow sources. Prerequisites for this method are a standard personal computer, an AVD convertor board and a measuring cylinder. It is based on a nonlinear transfer function, i.e. the relation between transducer output and flow rate is a parabola. This nonlinearity is important as it almost certainly assures that eqns. 1 and 2 are linearly independent; the flow patterns are different in every measurement. A test for the theoretical possibility of linear dependence can easily be incorporated into the method.

When six flow meters of the same type (Dantec 1000) were linearised using the described method, we found that the offset values differed considerably between different devices but remained stable over time. As all transducers were connected to the same amplifier, this difference must be ascribed to differences between the transducers. In practice, an individual offset correction needs to be used for each transducer. The offset variability $(12 \mathrm{mV}$ on average or approximately $0.05 \mathrm{ml} \mathrm{s}^{-1}$ ) implies that, roughly speaking, flow rate values below $0.1 \mathrm{ml} \mathrm{s}^{-1}$ cannot be detected. As a consequence, measurements at low flow rates with this transducer are inaccurate (left-hand column, Table 3 , on average $20 \%$ error in volume). Such very low flow rates occur frequently in urodynamics, e.g. in adult males with obstruction problems and in children. Usually the measured flow rate is integrated to derive the voided volume, which is compared to the volume infused into the bladder to verify if the bladder was emptied completely. The difference is used as an estimate of the amount of post-void residual urine, which is a very important parameter in urodynamics. It is used in the calculation of bladder contractility parameters (GRIFFITHS et al, 1986) for example. The data show that, in the case of low flow rates, voided volumes should be assessed by a measuring cylinder and not derived from the flow rate measurements.

The accuracy of the rotating disk flow meters in the case of 'normal' flow rates was in accordance with the manufacturer's specifications, which we find acceptable for urodynamics. Although the voided volume calculated by the average parameter values was significantly less accurate (in statistical terms) than the voided volume calculated with the 'optimal' parameters, we feel that the advantage of using equal parameters for different transducers outweights the (on average) small error thus introduced.

\section{Conclusions}

In summary, we can state that the Dantec 1000 rotating disk flow transducer can be linearised using the described method in such a way that flow rates can be measured accurately. It must be noted, however, that the measurement accuracy of this type of flow meter for small flow rates is limited.

Acknowledgment-Electronic equipment to control and amplify the flow rate transducers was designed and built by Henk van de Giessen, Hans de Haan and Hans van Rhijn, Central Instrumentation Department, Erasmus University, Rotterdam.

\section{References}

COOLSAET, B. L. R. A., and VAN DUYL, W. A. (1981): 'Principles of bladder function and uradynamics.' Laméris Medische apparaten S.A., Oudestraat 10, B2630 Aartselaar, Antwerpen, Belgium.

GRIFFITHS, D. J. (1980): 'Urodynamics: the mechanics and hydrodynamics of the lower urinary tract: Medical Physics Handbooks 4' (Adam Hilger Ltd., Bristol, UK)

GRIFFITHS, D. J., CONSTANTINOU, C. E., and VAN MASIRIGT, R. (1986): "Urinary bladder function and its control in normal females,' Am. J. Physiol., 251-2, pp. R225-R230

ROLIEMA, H. J. (1981): 'Uroflowmetry in males, reference values and clinical application in benign prostatic hypertrophy.' $\mathrm{PhD}$ thesis, Groningen, The Netherlands

ROWAY, D., MCKENZIE, A. L., MCNEE, S. G., and GLEN, E. S. (1977): 'A technical and clinical evaluation of the Disa Uroflowmeter,' Br. J. Urol., 49, pp. 285-291

Tammen, H. (1971a): 'Miktiograph 7005,' Acta Medicotech., 19, pp. $10-13$

TAMMEN, H. (1971b): 'Miktiographie-Ein Beitrag zur Harnflussmessung,' Urologe, 10, pp. 140-141

VON GARRELTS, B., and STRANDELL, P. (1972): "Continuous recording of urinary flow-rate,' Scand. J. Urol. Nephrol., 6, pp. 224-227 